\title{
VARIAÇÃO TEMPORAL NOS RECIFES DE CORAIS DE MARAGOGI, APA COSTA DOS CORAIS (2010 - 2013).
}

\author{
Camila BRASIL Louro da Silveira ${ }^{1}$ \\ Beatrice Padovani FERREIRA ${ }^{2}$ \\ Mariana S. COXEY ${ }^{3}$
}

Recebido em: 14/08/2014

Aceito em: $20 / 10 / 2014$

\section{RESUMO}

O presente trabalho teve como objetivo principal a comparação da estrutura da comunidade bentônica e cobertura coralínea entre 2010 (ano de potencial branqueamento) e 2013 nos recifes de corais de Maragogi. A pesquisa de campo foi realizada nas cristas recifais por duas metodologias do Protocolo Reef Check, que foram: point intercept transect (PIT) e foto quadrats (FOT). As anomalias de temperatura superficial no mar na área não foram suficientes para causar branqueamento nos corais dos sítios estudados em 2010. Ambos os métodos revelaram que a cobertura total de corais se manteve estável nos três anos de pesquisa. Os métodos revelaram resultados diferentes a nível de cobertura específica de corais e de cobertura de categorias indicadoras, que pôde ser em parte atribuído a dificuldade de amostragem do hidrocoral Millepora alcicornis. Ademais, comprovou-se a necessidade de correções e adaptações nos métodos atualmente utilizados, dado a variação estrutural dos recifes da área. Apenas desta forma, será possível a detecção de alterações de pequena e média escala nos recifes de corais de Maragogi, estratégia muito importante para o manejo sustentável da área.

Palavras chave: recife de coral, APA Costa dos Corais, branqueamento, cobertura de corais, metodologia de campo

\section{ABSTRACT}

The present study had as main objective: a comparison of the benthic community's structure and percentage of coral cover in 2010 (when bleaching occurred in several areas around the world) and in 2013 in the coral reefs of Maragogi. The field surveys were conducted on the reef crests following two methodologies of the Reef Check Protocol, which were: Point Intercept Transect (PIT) and Photo Quadrats (FOT). The sea surface anomalies in the area were not enough to cause severe bleaching in corals of the sites studied in 2010, and thus, bleaching was not observed in the photos. Both methods revealed that the total coral cover has remained stable over these three years of research. The methods revealed different results in terms of specific coral coverage and coverage of indicator categories, which could be attributed to problems with the sampling of the hydrocoral Millepora alcicornis. This research has proved the need for corrections and adjustments to the methods currently used, given the structural variation of the reefs in the area. Only doing so, will be possible to detect small/medium scale changes in the coral reefs Maragogi, very important strategy for the sustainable management of the area.

Key words: coral reefs, APA Costa dos Corais, bleaching, coral cover, field methodology

\section{INTRODUÇÃO}

Os recifes de corais são ambientes reconhecidos mundialmente como hotspots de diversidade ecológica (Roberts, 2002). Segundo estimativas recentes, os recifes de corais de águas rasas ocupam menos de $0,015 \%$ da área total do oceano e concentram mais de um quarto das espécies marinhas (NOAA). Em nenhum outro ambiente é possível encontrar

1 - Departamento de Oceanografia, Universidade Federal de Pernambuco - UFPE, CEP 50670901, Recife, PE, Brasil, www.ufpe.br/docean. 2 - Departamento de Oceanografia, Universidade Federal de Pernambuco - UFPE, CEP 50670-901, Recife, PE, Brasil, www.ufpe.br/docean 3 Instituto Recifes Costeiros, R. Samuel Hardman s/n, Tamandaré Pernambuco CEP: 55578-000, Brasil 
Silveira, Camila BRASIL Louro da; FERREIRA, Beatrice Padovani; COXEY; Mariana S. Variação temporal nos recifes de corais de Maragogi, Apa Costa dos Corais (2010 - 2013).

tamanha diversidade em um espaço tão reduzido. Recifes coralíneos são formados em sua maioria, em águas tropicais rasas e confinados a uma faixa circumtropical que tem seus limites latitudinais em $20^{\circ} \mathrm{N}$ e $20^{\circ} \mathrm{S}$. As águas marinhas nessa área podem apresentar as variáveis ambientais que permitem a simbiose alga-coral necessária para um recife coralíneo se formar e se manter. Algumas dessas características envolvem temperatura alta e consistente (mínimo de $18^{\circ} \mathrm{C}$, máximo de $29^{\circ} \mathrm{C}$ ), alta incidência de luz solar, alta salinidade e pouco material em suspensão na água (Kleypas et al, 1999).

A importância ecológica dos ecossistemas coralíneos é inegável. Faz-se necessário salientar também sua importância física, i.e, atuam como proteção da costa contra a ação erosiva hidrodinâmica de ondas; além da importância econômica e social. Segundo Wilkinson (2002), cerca de 500 milhões de pessoas residentes em países em desenvolvimento dependem de forma direta ou indireta de recifes de corais. Apesar da óbvia importância em diferentes âmbitos, estes ambientes estão sendo cada vez mais destruídos por uma combinação de impactos naturais e antrópicos, de pequena e larga escala. O somatório de impactos, a partir de uma determinada intensidade, recorrência e/ou duração, pode ocasionar uma mudança funcional de dominância, reduzindo a biodiversidade de forma significativa nos recifes impactados (West e Salm, 2003; Hughes et al., 2007; Nyström et al., 2008). Sobrepesca, degradação dos ambientes físicos, aumento na sedimentação, ocupação de zonas costeiras e poluição são alguns exemplos de impactos antrópicos sofridos por ambientes recifais (Jackson et al, 2001; Wilkinson, 2008). Como fatores "naturais", cita-se principalmente a acidificação dos oceanos (Hoegh-Guldberg et al, 2007) e o aumento da temperatura superficial marinha (SST). Estes impactos são em muito aumentados em intensidade e/ou frequência por influência antropogênica. A elevação da temperatura pode ser dada de forma global ou regional, ou como um somatório das duas. O El Niño - Southern Oscillation (ENSO) tem fortes consequências no ambiente recifal e está associado a eventos globais de branqueamento de corais, alguns com alta taxa de mortalidade coralínea e perda de biodiversidade associada. Um exemplo muito citado (e.g Hoegh-Guldberg, 1999; Glynn et al, 2001; Sheppard et al., 2002) corresponde ao ENSO de 1998, que foi o evento global de branqueamento mais extenso até então (GOREAU et al, 2000). Este evento causou mortalidade em diversos recifes do mundo e de certa forma, impulsionou a necessidade de mais estudos acerca do impacto/consequências e da observação de eventos de branqueamento em maior escala.

Recifes de corais são, portanto, áreas prioritárias para o manejo e a conservação marinha. Tendo em mente sua importância, na década de noventa iniciou-se a implantação de um programa de monitoramento global que permitisse uma visão mais quantitativa do status dos recifes no mundo. Com a crescente preocupação com impactos de larga escala em ambientes coralíneos e a necessidade de manutenção e preservação da fauna e flora associadas a estes ambientes, foi criada uma rede de monitoramento global de recifes de corais (Wilkinson, 2008). Em 1997, criou-se então a GCRMN - Global Coral Reef Monitoring Network das Nações Unidas, em um esforço conjunto a partir da ICRI - International Coral Reef Initiative. Os objetivos principais da GCRMN envolvem, entre outros: fortalecer o conhecimento científico do status e tendências em ecossistemas coralíneos ao redor do mundo; disponibilizar dados referentes a programas de monitoramento; fortalecer a comunicação e integração entre países membros do GCRMN; e conectar pessoas e organizações a fim de monitorar aspectos sociais, ecológicos, culturais e econômicos de regiões-alvo (GCRMN).

No Brasil, país membro da GCRMN, estão localizados os únicos complexos recifais coralíneos do Atlântico Sul. Recifes coralíneos e areníticos estão distribuídos ao longo de aproximadamente $3.000 \mathrm{~km}$ de costa, todos na região Nordeste (divisão política) (Amaral e Jablonski, 2005; Ferreira e Maida, 2006). A fauna recifal brasileira é pobre e apresenta baixa diversidade de espécies (18 espécies de corais pétreos - construtores de recifes), porém, apresenta alto endemismo. Dez destas 18 espécies são apenas encontradas em mares brasileiros.

Após a observação de impactos sofridos por recifes brasileiros (e.g Leão et al, 1996; Costa et al, 2000; Castro e Pires, 2001), em 2001, iniciou-se o projeto "Monitoramento de Recifes de Corais do Brasil", com objetivo de estabelecer um programa nacional de monitoramento e integrar as Unidades de Conservação existentes. O protocolo Reef Check foi selecionado para

Tropical Oceanography, Recife, v. 42, n. 2, p. 208-225, 2014. 
Silveira, Camila BRASIL Louro da; FERREIRA, Beatrice Padovani; COXEY; Mariana S. Variação temporal nos recifes de corais de Maragogi, Apa Costa dos Corais (2010 - 2013).

fornecer os dados qualitativos e quantitativos acerca dos recifes brasileiros. Este protocolo se utiliza de métodos de censo visual subaquático para estimar e calcular a cobertura relativa de cada substrato e organișmo indicador no recife (i.e. corais, peixes e invertebrados) e assim, avaliar sua condição. É caracterizado como rápido, simples e barato, principalmente se comparado a outros protocolos em utilização atualmente (e.g AGRRA). Além disso, é mundialmente utilizado (mais de 80 países) e estimula a participação de membros da comunidade de forma voluntária, uma vez que devidamente treinados (Hodgson et al, 2004) . Desta forma, estimula também o interesse da sociedade nos ecossistemas recifais estudados, aumentando a preocupação e consciência ambiental.

O Protocolo Reef Check fornece informações quantitativas importantes acerca da saúde recifal e é considerado ideal para o monitoramento de grandes áreas como a costa brasileira. 0 método de pesquisa utilizado para inferência da cobertura coralínea é o Point Intercept Transect (PIT), que estima a porcentagem de cobertura dos diferentes substratos e organismos.

Com o intuito de preservar a biodiversidade marinha de uma parcela importante do litoral nordestino, foi implementada entre os estados de Pernambuco e Alagoas, a APA Costa dos Corais (APACC). A APACC foi criada por Decreto Federal em 23 de outubro de 1997 (Brasil. Decreto de Lei no 6.902). Esta unidade de conservação federal é a mais extensa do Brasil, abrangendo uma área total de aproximadamente $4135 \mathrm{~km}^{2} \mathrm{em} 135 \mathrm{~km}$ de litoral. É a primeira no país a incluir recifes costeiros, reconhecendo a importância ecológica, ambiental e econômica desses ecossistemas (Maida e Ferreira, 1997).

A zona costeira de Maragogi, pertencente à APACC, está submetida a uma zonação de uso e atividades permitidas. A avaliação das características de diversidade e susceptibilidade dos recifes possibilita estratégias importantes de manejo, imprescindíveis no caso da necessidade de tomadas de decisões mitigadoras. Como já observado, para que os objetivos do manejo sustentável sejam alcançados, torna-se ainda mais necessário o monitoramento que reflita de forma fiel impactos e alterações no ambiente. Para tal, é imprescindível que as metodologias corretas sejam aplicadas, de forma a representar de forma confiável a biodiversidade do ecossistema.

Em 2010, análises de anomalia de temperatura da superfície marinha (SSTa) em diversos pontos da costa brasileira (Ferreira et al, 2013; Miranda et al, 2013) revelaram a possibilidade da ocorrência de branqueamento. Estas máximas de temperatura foram vinculadas a um aquecimento de larga escala associado ao El Niño 2009/2010. Como regra geral (Brown, 1997; NOAA), acredita-se que anomalias iguais ou maiores que $1^{\circ} \mathrm{C}$ com duração igual ou maior que quatro semanas sejam capazes de causar branqueamento em massa. Atualmente, o branqueamento é tido como a maior ameaça aos recifes de corais (Hoegh-Guldberg, 1999).

Um dos maiores problemas no caso de aumento global de temperatura é que do ponto de vista do manejo, não é possível em curto prazo, acessar diretamente a fonte da mudança a fim de suspendê-la ou revertê-la (Nyström et al, 2008). No entanto, muitas vezes é possível controlar impactos locais como a sobrepesca e a poluição costeira, dando ao recife impactado possibilidades de recuperação. Detectar a possibilidade da ocorrência e atuar diretamente no ambiente são portanto, ações imprescindíveis para o controle do resultado final do impacto sofrido pelo ambiente. Para que isso fosse factível, foi proposto a realização do cálculo das SSTa na área de Maragogi desde 2000 até o presente, com atenção especial para o ano de 2010 (ano de ocorrência de El Niño) e a comparação da composição específica observada neste ano e em 2013. É necessário salientar a importância desta análise, posto que já existe previsão de El Niño com impactos na costa brasileira para o ano de 2014 (INPE - Instituto Nacional de Pesquisa).

\section{DESCRIÇÃo DE ÁREA}

Os locais selecionados para análise dos dados e aplicação das técnicas de campo foram os recifes de corais de Maragogi pertencentes à Área de Proteção Ambiental Costa dos Corais (Figura 1). É uma área de plataforma rasa onde estão localizadas várias linhas de recifes, principalmente costeiros. Segundo Ferreira e Maida (2006), os recifes de Maragogi têm biodiversidade relativamente alta e abrigam um total de seis espécies de corais e 26 espécies de peixes.

Tropical Oceanography, Recife, v. 42, n. 2, p. 208-225, 2014. 


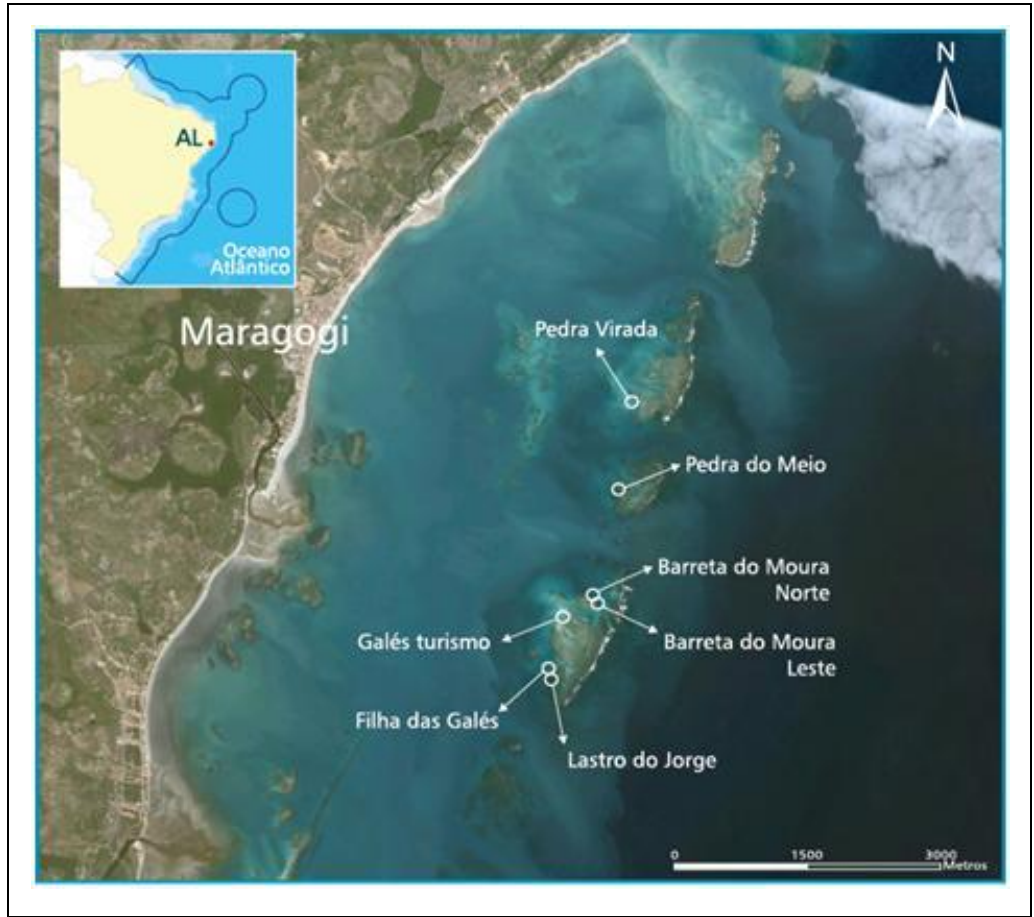

Figura 1 - Distribuição dos recifes costeiros de Maragogi acessados pelo Reef Check Brasil (imagem cedida pelo Reef Check Brasil UFPE/IRCOS/MMA).

Os recifes acessados foram: Pedra do Meio, Barreta do Moura Leste, Barreta do Moura Norte, Filha das Galés e Lastro do Jorge.

O recife conhecido como Pedra do Meio está classificado como Zona de Proteção de Vida Marinha (ZPVM), onde nenhuma atividade antrópica está permitida, salvo pesquisa científica autorizada. Representa o mais alto grau de conservação de UC. Os demais recifes estudados são Zonas de Visitação (ZV), áreas destinadas ao uso ordenado de turismo de base comunitária ou empresarial. Nestas áreas, nenhuma atividade predatória (e.g pesca, coleta de organismos) é permitida.

Os recifes de Maragogi estão localizados a uma distância média entre 2,5 e 3,5km da costa alagoana. A proximidade da costa possibilita uma maior exploração turística nestes ambientes e mais de 60 mil turistas visitam a área por ano. O turismo infere fontes diretas de impacto no ambiente (e.g pisoteio, resíduos e lixo, alimentação artificial oferecida a peixes por turistas). Além disto, a zona costeira da Costa dos Corais sofre também com a grande sedimentação de origem terrestre devido a atividades relacionadas à agricultura. Cita-se também a degradação provavelmente irreversível causada pela extração de corais muito realizada em décadas passadas.

\section{MATERIAIS E MÉTODOS}

Em 2010 foram aplicadas na área as técnicas de campo Point Intercept Transect e Foto Quadrats. No ano de 2013, como proposto pelo INCT AmbTrop, o Método de transectos em Faixa foi adicionado ao protocolo Reef Check. Os organismos são registrados em grupos funcionais (e.g Coral duro) e da forma mais específica possível (e.g Siderastrea stellata).

O protocolo Reef Check consiste em censos visuais subaquáticos realizados ao longo de transectos (quatro transectos de 20 metros cada, ou 100 metros ao todo). Em todos os anos, os transectos foram cuidadosamente colocados em um local específico (na crista recifal), como identificado pelas linhas vermelhas na figura 2 . 
Silveira, Camila BRASIL Louro da; FERREIRA, Beatrice Padovani; COXEY; Mariana S. Variação temporal nos recifes de corais de Maragogi, Apa Costa dos Corais (2010 - 2013).

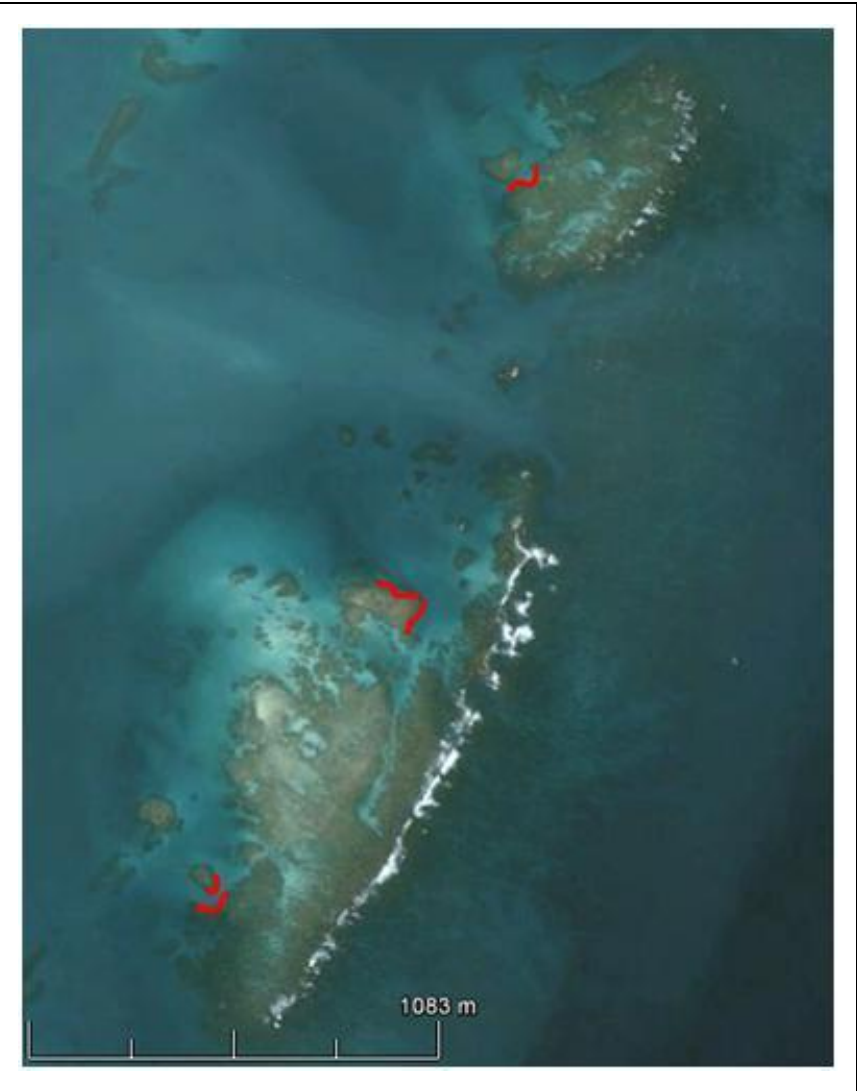

Figura 2 - Localização da área de estudo em cada um dos recifes acessados em Maragogi.

\section{i) Foto Quadrat}

Ao longo de cada um dos quatro transectos de cada recife, foram lançados em média 10 quadrats de foto. Assim, cada site contou com, aproximadamente, 40 fotos.

Para cálculo das porcentagens de cobertura foi utilizado o software Coral Point Count with Excel extensions - CPCe (KOHLER e GILL 2006). O CPCe sorteia um determinado número de pontos em cada imagem; é então registrado em uma planilha a classe bentônica correspondente ao ponto sorteado. O cálculo da porcentagem da cobertura em cada foto é dado por (\# registros/\#pontos)*100;

As imagens foram analisadas com 15 pontos aleatórios por foto.

\section{ii) Point Intercept Transect}

Consiste em marcações feitas a cada $0,5 \mathrm{~m}$. O organismo ou substrato bentônico observado diretamente abaixo das marcações é registrado na planilha para posterior contagem e estimativa de sua respectiva porcentagem de cobertura (ROELFSEMA et al., 2004). Esse método foi utilizado por protocolos como Reef Check, MBRS SMP, Reef Keeper, entre outros (HILL e WILKINSON, 2004). A porcentagem de cada cobertura foi então calculada pela fórmula (\# registros/\#pontos)*100;

\section{Análises dos dados}

Para análise de ocorrência de branqueamento e estresse térmico, foram utilizados dados disponibilizados pelo programa Coral Watch (NOAA). Foram utilizados dados já previamente calculados de Heat Week e Thermal Stress.

Segundo metodologia proposta para a identificação de hotspots de branqueamento coralíneo pela NOAA, a climatologia é definida como a temperatura média de cada mês no período entre 1981 a 2000. Desta forma, por exemplo, a temperatura base para o cálculo da anomalia para o mês de janeiro seria: a média das temperaturas médias mensais de Janeiro de 1981 a 2000. Foi escolhido trabalhar com dados semanais (Heat Week), pois o efeito da 
Silveira, Camila BRASIL Louro da; FERREIRA, Beatrice Padovani; COXEY; Mariana S. Variação temporal nos recifes de corais de Maragogi, Apa Costa dos Corais (2010 - 2013).

anomalia no ambiente recifal é também dependente de sua duração em semanas. A anomalia é então calculada como o resultado entre a subtração do valor da média mensal da temperatura semanal observada: SSTa = SST - Média mensal climatológica.

Para análise estatística das diferenças significativas entre os métodos, foi utilizado ANOVA One-way, como proposto por Dodge et al. (1982). Para as análises espaciais restantes que envolviam mais de um fator de significância (e.g entre recifes), foi seguida a metodologia proposta por Beenaerts e Bergue (2007) em estudo semelhante que utilizou a ANOVA two-way. Para análise com múltiplos fatores, foram realizados testes com PERMANOVA.

Para a análise temporal, primeiramente foi sugerida a utilização da ANOVA repeated measures, como proposto por Bruno e Selig (2007) em verificação de declínio na cobertura coralínea utilizando uma série temporal no Indo-Pacífico. No entanto, posto que, apesar da tentativa de fidelidade espacial, é possível que os transectos não tenham sido colocados exatamente no mesmo local e na mesma ordem (i.e transecto 1, 2, 3 e 4 nas mesmas linhas em 2010 e 2013), utilizamos também a ANOVA two-way ou PERMANOVA. Para facilitar a observação dos agrupamentos, também foram utilizados como métodos adicionais análises multivariadas, gráficos de escala multidimensionais e análises de Cluster (e.g MDS Bray-Curtis) e análises de componentes principais (PCA) com testes Simper.

Os softwares utilizados foram o PAST (PAleontological STatistics) versão 3.1 (HAMMER et al, 2001) e o PRIMER 6 e Permanova+ (Plymouth Routines In Multivariate Ecological Research).

Tratamento e transformação dos dados para análise estatística: Para tentar corrigir a falta de normalidade e/ou a heterocedasticidade nos registros originais, os dados foram

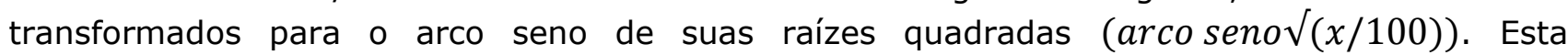
transformação é amplamente utilizada para dados de contagem expressos em porcentagens (SANTANA e RANAL, 2000; BIANCONI et al. 2008), como é o caso deste trabalho.

\section{RESULTADOS}

\section{Ocorrência de estresse térmico/hotspot de branqueamento em 2010 em Maragogi}

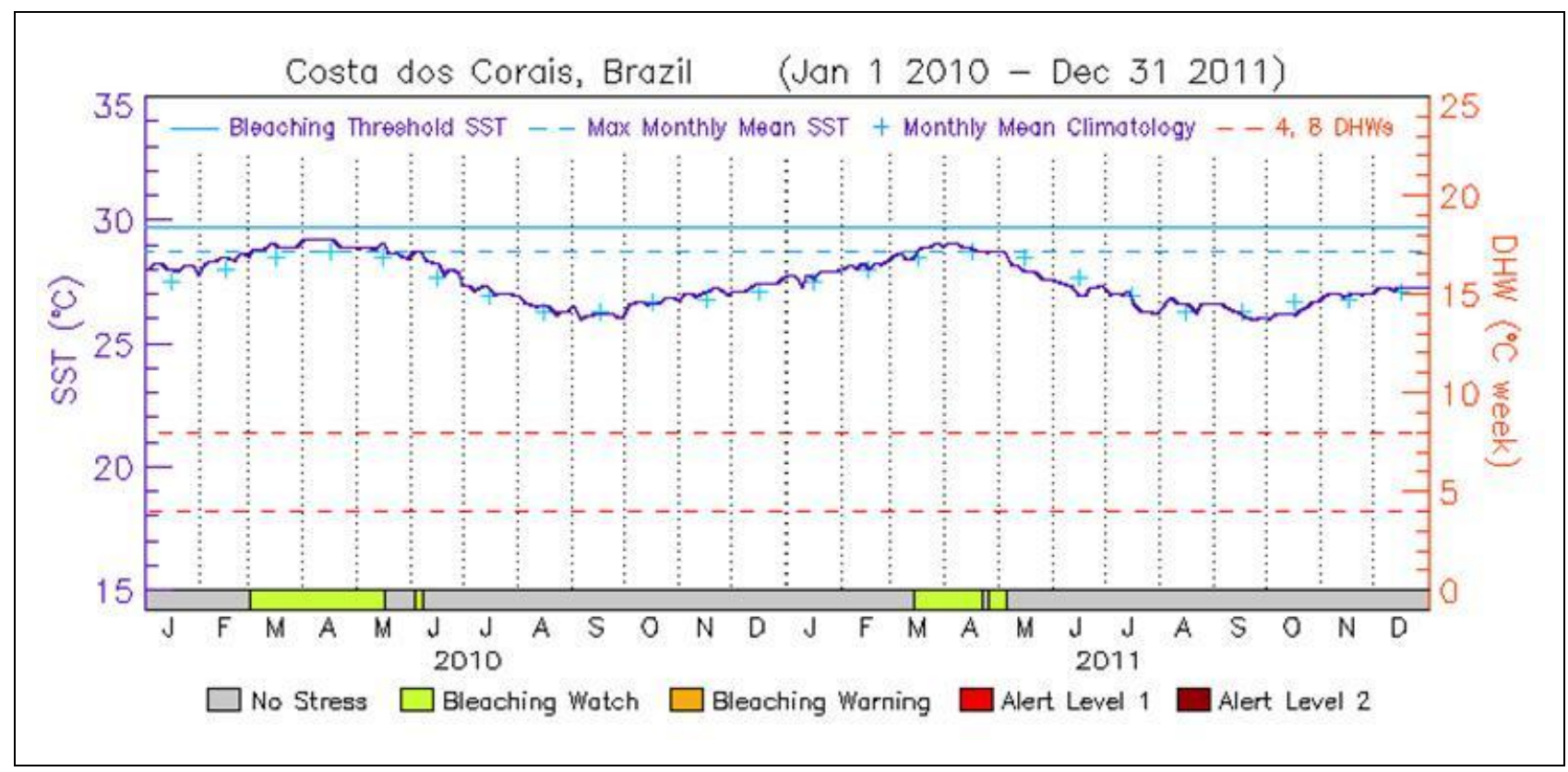

Figura 3 - Gráfico representativo das temperaturas superficiais do mar semanais de janeiro de 2010 a dezembro de 2011. Dados de temperatura limítrofe para branqueamento (Bleaching threshold SST); temperatura máxima mensal (Max monthly SST) e climatologia mensal (Monthly mean climatology). Fonte: NOAA (em coralreefwatch.noaa.gov) 
Silveira, Camila BRASIL Louro da; FERREIRA, Beatrice Padovani; COXEY; Mariana S. Variação temporal nos recifes de corais de Maragogi, Apa Costa dos Corais (2010 - 2013).

Os resultados do Coral Reef Watch (Fig 3) indicam que não houve anomalia persistente ou intensa o suficiente para causar branqueamento na área da Costa dos Corais entre 2010 e 2011, apesar do reportado para outros locais do mundo.

\section{Análise temporal $2010 \times 2013$}

Em 2010 e 2013, duas técnicas de campo foram utilizadas para avaliar os recifes de corais de Maragogi: PIT (Point Intercept Transect) e FOT (Fotoquadrat) (Figura 4). Quatro transectos por sítio, ou 16 transectos/ano ao total foram realizados em campo simultaneamente $e$ posicionados nas cristas dos recifes de quatro sítios/sites diferentes: Barreta do Moura Leste (MLES), Barreta do Moura Norte (MNOR), Filha das Galés (FGAL) e Pedra do Meio (PMEI). A análise temporal da cobertura coralínea será, portanto, apresentada primeiramente por metodologia. Desta forma, será possível também avaliar a diferença de cada método no que diz respeito a estas análises.

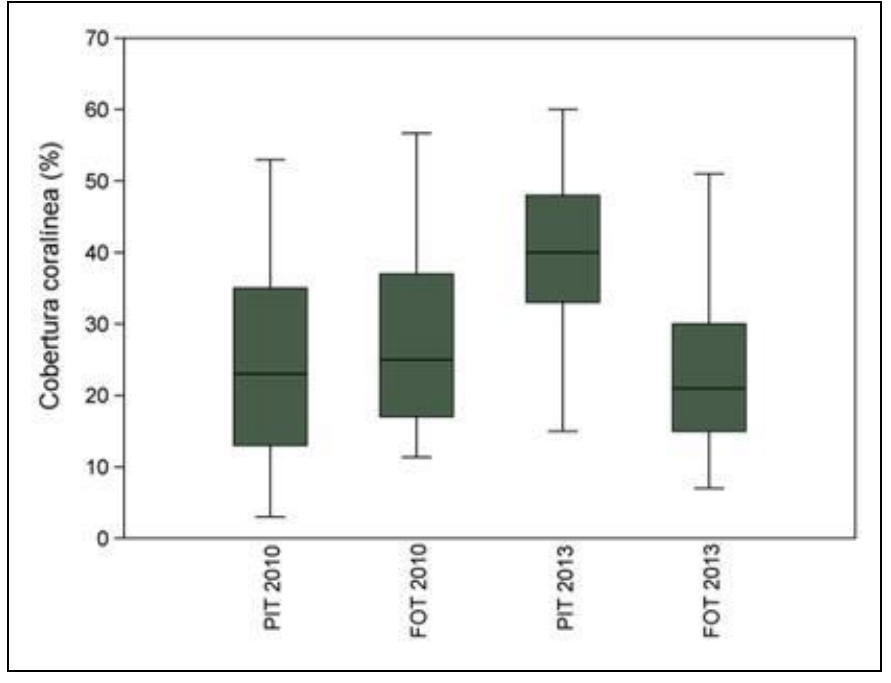

Figura 4 - Médias das coberturas coralíneas obtidas pelos métodos FOT e PIT em 2010 e 2013 nos sítios Barreta do Moura Leste, Barreta do Moura Norte, Filha das Galés e Pedra do Meio.

\section{1) PIT (Point Intercept Transect)}

Para esta análise foram utilizados os dados de 32 transectos nos quatro sítios monitorados tanto no ano 2010 como em 2013, cada ano com um total de 16 transectos - quatro por sítio. Os resultados da cobertura coralínea geral e por site/sítio e ano, registrados através do método PIT estão ilustrados na Figura 5, sendo possível observar um aumento da cobertura de coral total (i.e somatório das coberturas relativas das espécies registradas) nos registros do PIT para todos os sites amostrados. As médias totais variaram de 25\% em 2010 para 39\% em 2013. Nos sítios, a maior variação foi encontrada em Filha das Galés, que variou de $11 \%$ em 2010 para $44 \%$ em 2013. O sítio com a menor variação foi Pedra do Meio, que se manteve em $31 \%$ nos dois anos de estudo.

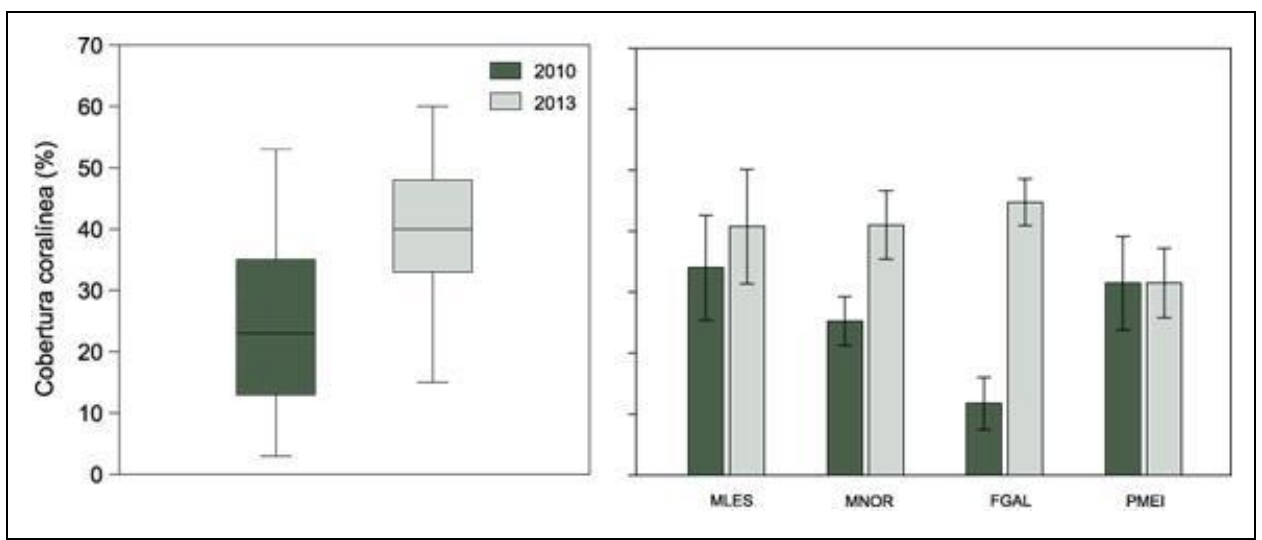

Figura 5 - Média total das porcentagens de cobertura de coral para 2010 e 2013 (esquerda) e média das porcentagens de cobertura coralínea total por sítio e ano, obtidas pelo método PIT. 
Silveira, Camila BRASIL Louro da; FERREIRA, Beatrice Padovani; COXEY; Mariana S. Variação temporal nos recifes de corais de Maragogi, Apa Costa dos Corais (2010 - 2013).

Para testar se havia diferenças entre os sítios amostrados, e entre as amostragens em 2010 e 2013, os dados transformados em arcsen $(\sqrt{ } X)$ foram analisados através de uma ANOVA Two-way (Tabela 1) na qual foi possível observar que: i) os sites não mostram diferença entre si em relação à cobertura de coral total $(p>0,05)$; ii) há diferença significativa na porcentagem de cobertura coralínea total entre os anos de 2010 e 2013 ( $p<0,05)$ e iii) a interação entre estes dois fatores não é significativa. Através do gráfico de interação é possível verificar que essa diferença é proveniente dissimilaridade entre a cobertura total observada em Filha das Galés em 2010 e a observada em 2013 (Figura 6).

Tabela 1 - ANOVAs two-way para cada sítio

\begin{tabular}{l|r|c|c|c|c}
\multicolumn{1}{c|}{ Fator } & g.I. & SQ & MQ & F & p \\
\hline Site & 3 & 0.060 & 0.020 & 0.936 & 0.439 \\
\hline Ano & 1 & 0.212 & 0.212 & 9.869 & $0.004 *$ \\
\hline Interação & 3 & 0.185 & 0.062 & 2.869 & 0.058 \\
\hline Residual & 24 & 0.516 & 0.021 & & \\
\hline
\end{tabular}

Uma segunda análise foi realizada a fim de verificais quais dos sítios exibiam diferença significativa entre as coberturas coralíneas totais. Para isso, foram utilizadas ANOVAs one-way (Tabela 2), que demonstraram que a diferença significativa geral observada para os anos de 2010 e 2013 se deu somente em detrimento da grande dissimilaridade entre a cobertura total observada em Filha das Galés em 2010 e a observada em 2013.

Tabela 2 - ANOVAs one-way para cobertura coralínea total dos sítios amostrados em 2010 e 2013 pelo PIT

\begin{tabular}{|c|c|c|c|c|c|c|c|}
\hline MLES & & MNOF & & FGAL & & PMEI & \\
\hline $\mathbf{F}$ & $p$ & $\mathrm{~F}$ & $p$ & $\mathrm{~F}$ & $p$ & $\mathrm{~F}$ & $p$ \\
\hline 0,27 & 0,62 & 5,3 & 0,06 & 25,6 & $0,002 *$ & 0,001 & 0,97 \\
\hline
\end{tabular}

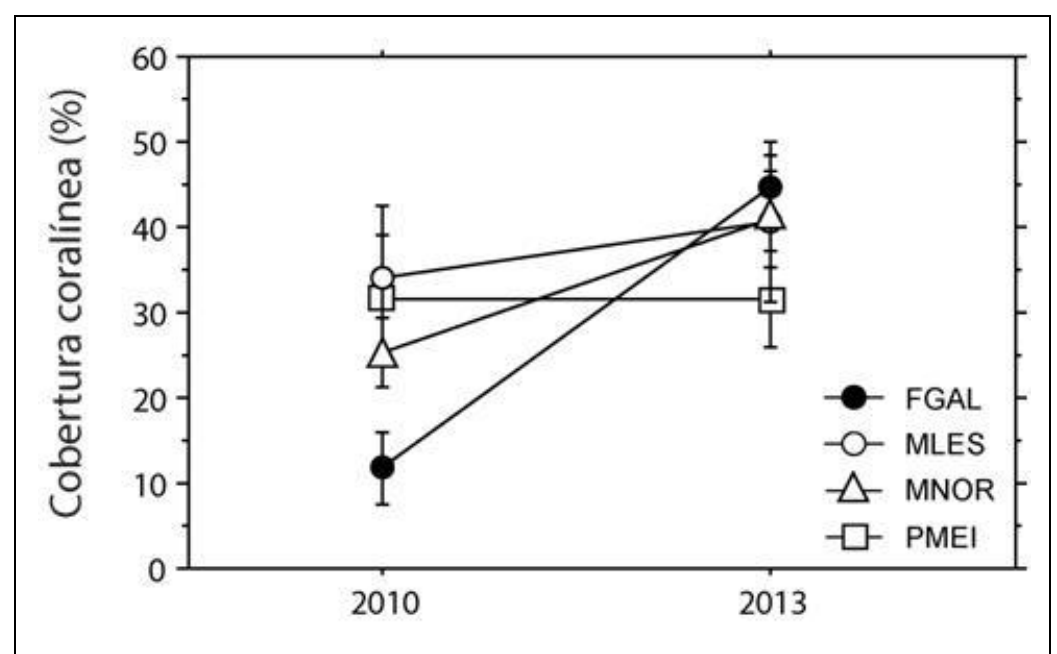

Figura 6 - Gráfico de interação ano e sítio para PIT.

Para testar se a cobertura da fauna coralínea aumentou como um todo (ou seja, se houve aumento de cobertura de várias espécies), segundo os dados do PIT, realizou-se um teste SIMPER que analisa as similaridades das porcentagens e as contribuições de cada espécie para os dados de dissimilaridade (Tabela 3). 
Silveira, Camila BRASIL Louro da; FERREIRA, Beatrice Padovani; COXEY; Mariana S. Variação temporal nos recifes de corais de Maragogi, Apa Costa dos Corais (2010 - 2013).

Tabela 3 - Resultados do SIMPER para similaridades entre as espécies de corais em 2010 e 2013 para o PIT.

\begin{tabular}{c|c|c|c|c|c|c|}
\hline \multicolumn{7}{c}{$2010-2013$} \\
\hline Sp & Av.Abund & Av.Abund & Av.Diss & Diss/SD & Contrib\% & Cum.\% \\
\cline { 3 - 7 } Mial & 0,43 & 0,57 & 18,69 & 1,23 & 41,9 & 41,9 \\
\cline { 4 - 7 } Mha & 0,07 & 0,21 & 12,82 & 1,07 & 28,7 & 70,6 \\
\cline { 3 - 7 } Mi br & 0,13 & 0,02 & 7,63 & 1,23 & 17,1 & 87,7 \\
\hline
\end{tabular}

Onde: Mi al - Millepora alcicornis; Mha - Mussismilia harttii; Mibr - Millepora braziliensis.

A Figura 7 ilustra a porcentagem de Millepora alcicornis em comparação com a porcentagem total de cobertura coralínea registrada pelo PIT em cada sítio em 2010 e 2013. É possível notar claramente a contribuição dos dados referentes à espécie Millepora alcicornis para a dissimilaridade calculada entre 2010 e 2013. Nesta figura é possível observar que em Filha das Galés, a média de cobertura de Millepora alcicornis quase triplicou entre 2010 e 2013, passando de aproximadamente $9 \%$ para cerca de $40 \%$.

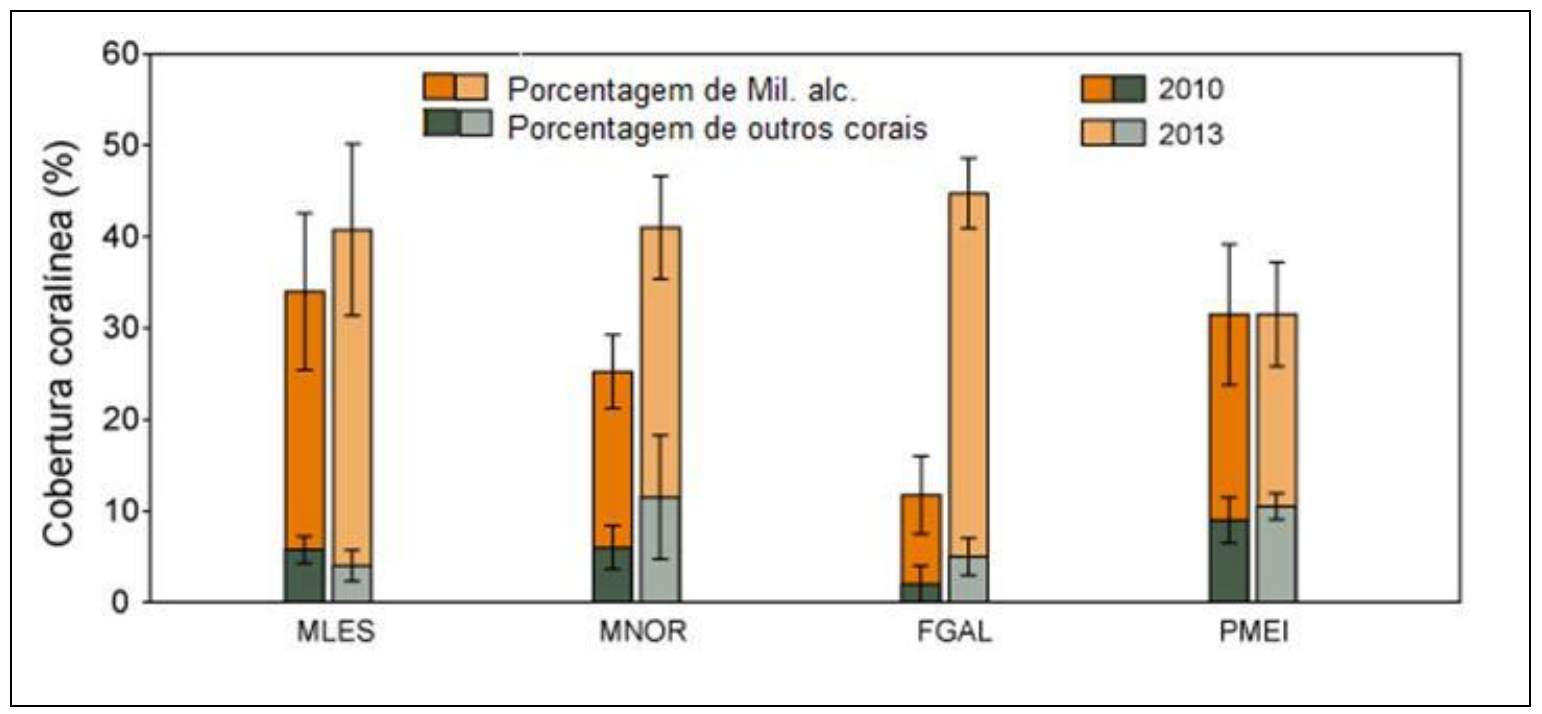

Figura 7 - Representação da porcentagem relativa de Millepora alcicornis comparada à porcentagem total de corais de outras espécies em cada sítio amostrado pelo PIT em 2010 e 2013.

Além dos dados referentes à cobertura coralínea (COR), é necessário também analisar outros grupos funcionais importantes nos recifes de Maragogi. Estes organismos/substratos são considerados indicadores de saúde recifal. As médias das coberturas dos principais grupos funcionais registrados para Maragogi encontram-se representados na Figura 8. 
Silveira, Camila BRASIL Louro da; FERREIRA, Beatrice Padovani; COXEY; Mariana S. Variação temporal nos recifes de corais de Maragogi, Apa Costa dos Corais (2010 - 2013).

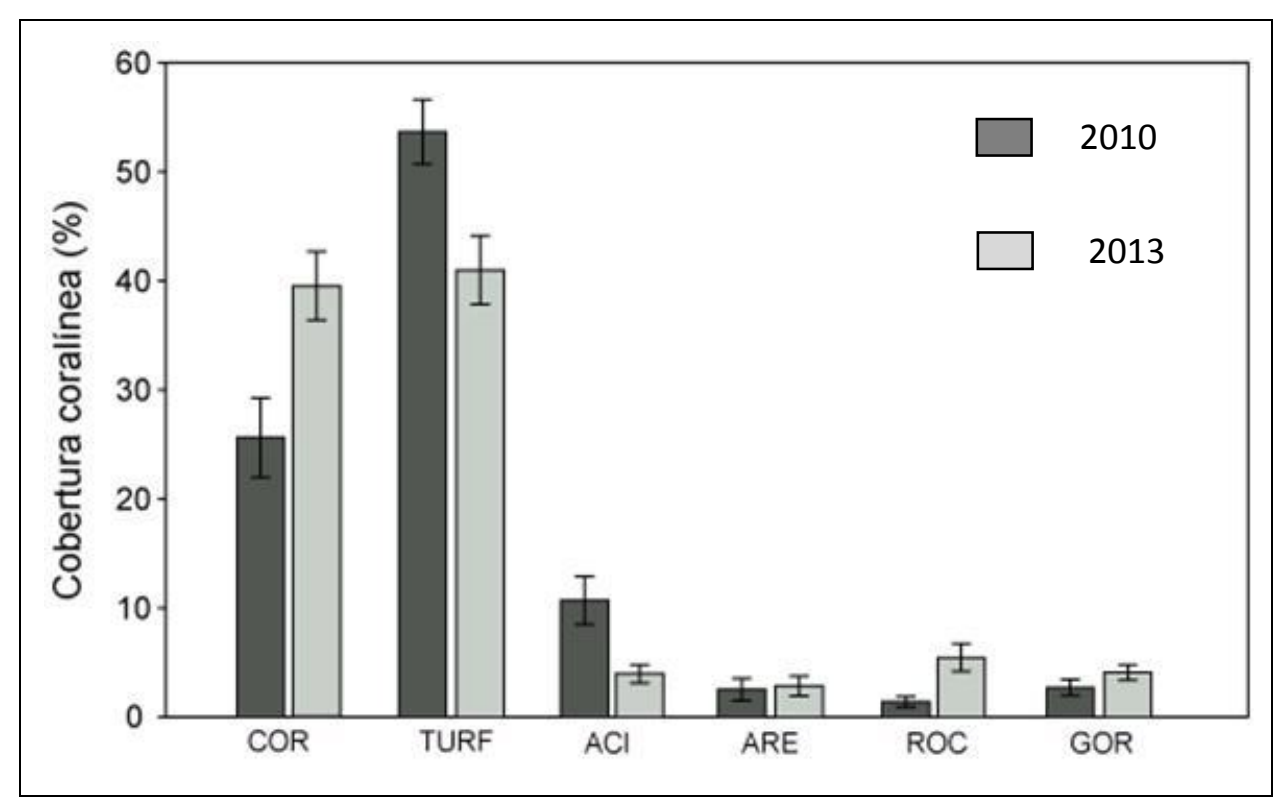

Figura 8 - Médias das coberturas de grupos indicadores obtidas pelo PIT em 2010 e 2013: COR - coral; TURF - macroalgas; ACI - alga calcária incrustante; ARE - areia ; ROC - rocha e GOR - gorgônia.

A análise estatística PERMANOVA two-way, utilizada para testar mais de uma variável, (Tabela 4) mostrou que i) os sítios não são diferentes entre si em relação aos grupos indicadores $(p>0,05)$; ii) há diferença significativa nas médias das coberturas de grupos indicadores entre os anos de 2010 e 2013 ( $p<0,05)$ e iii) a interação entre estes dois fatores não é significativa. Ao se retirar a categoria de coral duro (CD) da PERMANOVA verificou-se que os valores de $p$ continuam semelhantes à análise incluindo a categoria de coral, mostrando diferença entre os anos, similaridade entre os sites e que não há interação entre estes dois fatores.

Tabela 1 - PERMANOVA two-way de grupos de organismos e substratos indicadores

\begin{tabular}{l|cc|cc}
\hline & \multicolumn{2}{|c|}{ Com COR } & \multicolumn{2}{c}{ Sem COR } \\
\hline Fator & $\mathrm{F}$ & $p$ & $\mathrm{~F}$ & $p$ \\
Site & 1,233 & 0,286 & 1,479 & 0,178 \\
Ano & 9,48 & $0,001^{*}$ & 7,74 & $0,0007^{*}$ \\
Interação & 1,914 & 0,106 & 2,111 & 0,05 \\
\hline
\end{tabular}

Analisando a contribuição de cada categoria para a dissimilaridade entre os grupos de 2010 e 2013 (Tabela 5), observa-se que as classes de indicador têm contribuição semelhante, porém os maiores responsáveis pela diferenciação interanual são: Cobertura coralínea e alga calcária incrustante.

Tabela 5 - $\quad$ Resultados do SIMPER para similaridades entre as espécies de corais em 2010 e 2013 para o PIT.

\begin{tabular}{ccccccc}
\hline & $\begin{array}{l}\text { Group } \\
\mathbf{2 0 1 0}\end{array}$ & $\begin{array}{l}\text { Group } \\
\mathbf{2 0 1 3}\end{array}$ & & & & \\
\hline Sp & Av.Abund & Av.Abund & Av.Diss & Diss/SD & Contrib\% & Cum.\% \\
COR & 0,51 & 0,67 & 5,78 & 1,40 & 22,21 & 22,21 \\
ACI & 0,29 & 0,16 & 5,13 & 1,33 & 19,73 & 41,94 \\
TURF & 0,84 & 0,69 & 4,55 & 1,40 & 17,50 & 41,94 \\
\hline
\end{tabular}


Silveira, Camila BRASIL Louro da; FERREIRA, Beatrice Padovani; COXEY; Mariana S. Variação temporal nos recifes de corais de Maragogi, Apa Costa dos Corais (2010 - 2013).

\begin{tabular}{lcccccc}
\hline ROC & 0,07 & 0,2 & 4,02 & 1,34 & 15,45 & 59,44 \\
ARE & 0,10 & 0,11 & 3,30 & 1,08 & 12,69 & 87,58 \\
GOR & 0,12 & 0,17 & 3,23 & 1,23 & 12,42 & 100 \\
\hline
\end{tabular}

Gráficos de Escalonamento Multidimensional (MDS) foram utilizados para facilitar a visualização dos resultados da estrutura da comunidade dos recifes estudados em 2010 e 2013 (Figura 9a) e da estrutura da comunidade coralínea dos recifes da área em 2010 e 2013 (Figura 9b).

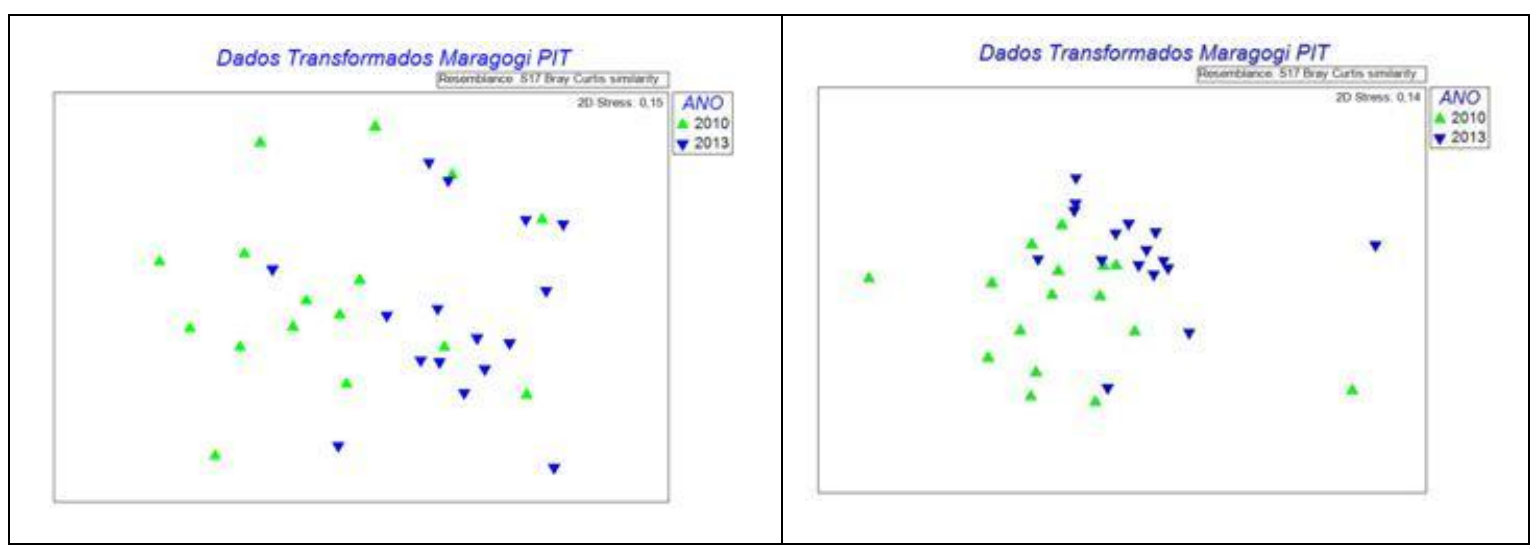

Figura 9 - MDS para composição da comunidade dos recifes de Maragogi obtida pelo método PIT. Cada amostra representa cada um dos transectos nos sítios estudados ( $n$ total=32): a) todos as classes indicadoras registradas; e b) comunidade coralínea em evidência.

\section{2) FOT}

As porcentagens de cobertura coralínea obtidas pelo método FOT em Barreta do Moura Leste, Barreta do Moura Norte, Filha das Galés e Pedra do Meio nos anos de 2010 e 2013 mostraram menores variações entre 2010 e 2013 pelo FOT. A maior variação encontrada foi em Filha das Galés, que em 2010 registrou 24\% de cobertura coralínea média e em 2013, apenas 16\% (Figura 10).

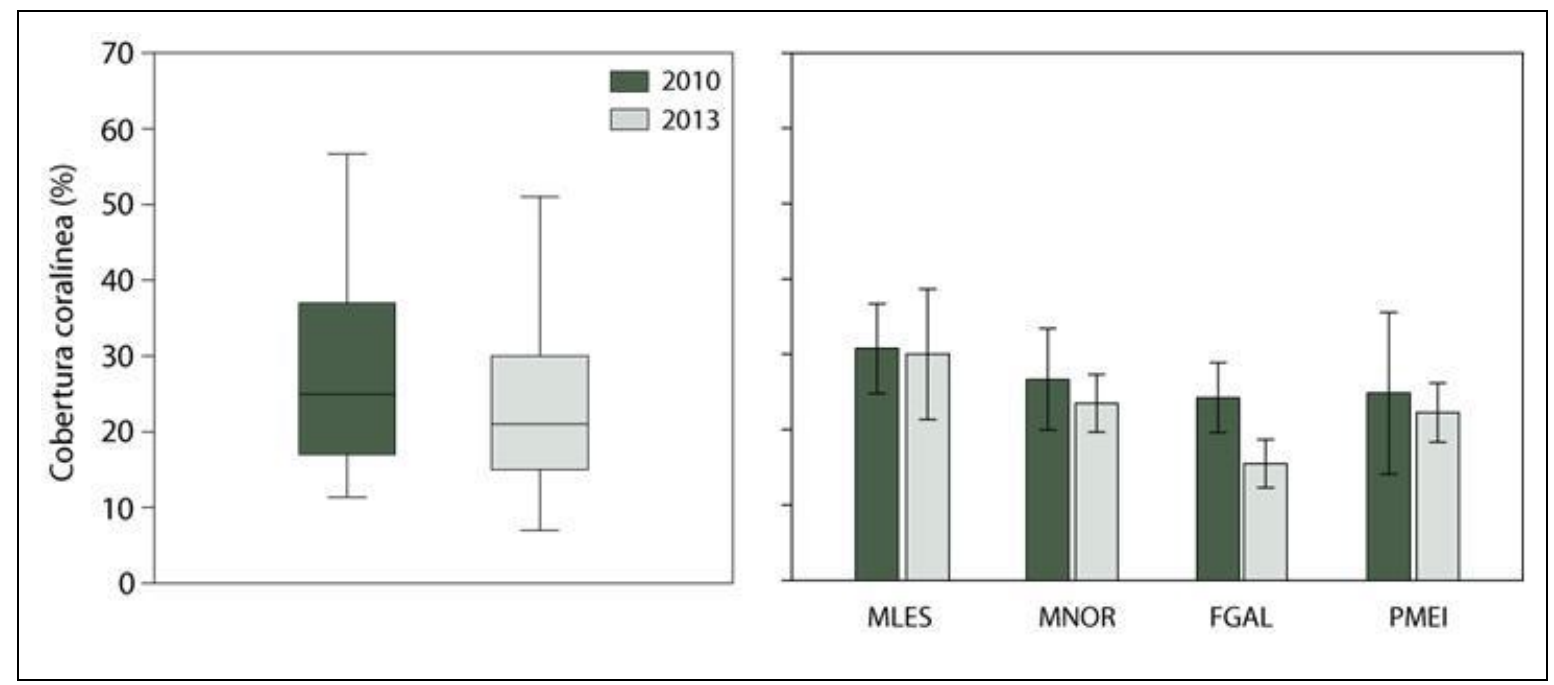

Figura 10 - Média total das porcentagens de cobertura de coral para 2010 e 2013 (esquerda) e média das porcentagens de cobertura coralínea total por sítio e ano, obtidas pelo método FOT.

Analogamente ao realizado para os resultados do PIT, os dados transformados de cobertura coralínea total foram testados estatisticamente pela ANOVA two-way (Tabela 6), que foi 
Silveira, Camila BRASIL Louro da; FERREIRA, Beatrice Padovani; COXEY; Mariana S. Variação temporal nos recifes de corais de Maragogi, Apa Costa dos Corais (2010 - 2013).

possível verificar, pelos valores $p$ de significância que: i) as coberturas coralíneas entre os sites e entre os anos de 2010 e 2013 são similares ( $p>0,05)$; ii) a interação entre estes dois fatores não é significativa. Os dados provenientes do método de foto-quadrat analisados pelo software CPCe não verificaram diferenças significativas na cobertura entre os sites ou entre os anos de 2010 e 2013.

Tabela 6 - ANOVA two-way para comparação das coberturas coralíneas entre os sites e anos de 2010 e 2013.

\begin{tabular}{lcc}
\hline Fator & $\mathbf{F}$ & $\boldsymbol{p}$ \\
\hline Ano & 0,696 & 0,413 \\
Site & 0,938 & 0,438 \\
Interação & 0,148 & 0,93 \\
\hline
\end{tabular}

O teste realizado para testar as possíveis diferenças entre coberturas específicas de grupos de corais (i.e escleractíneos e hidrocorais) foi a ANOVA two-way.

Tabela 7 - ANOVA two-way para comparação das coberturas de hidrocorais e escleractíneos nos anos de 2010 e 2013.

\begin{tabular}{lcc|cc}
\hline & \multicolumn{2}{c}{ Hidrocorais } & \multicolumn{2}{c}{ Escleractíneos } \\
\hline & $\mathrm{F}$ & $p$ & $\mathrm{~F}$ & $p$ \\
Ano & 0,019 & 0,891 & 2,821 & 0,107 \\
Site & 2,266 & 1,108 & 2,232 & 0,111 \\
Interação & 0,637 & 0,599 & 2,926 & 0,06 \\
\hline
\end{tabular}

Verificando-se, portanto, que em geral, a média das coberturas de mileporídeos (hidrocorais) não variou de forma significativa entre os anos ou entre os sites. De modo geral, o grupo dos escleractíneos também não apresentou variação significativa entre 2010 e 2013 (Figura 11).

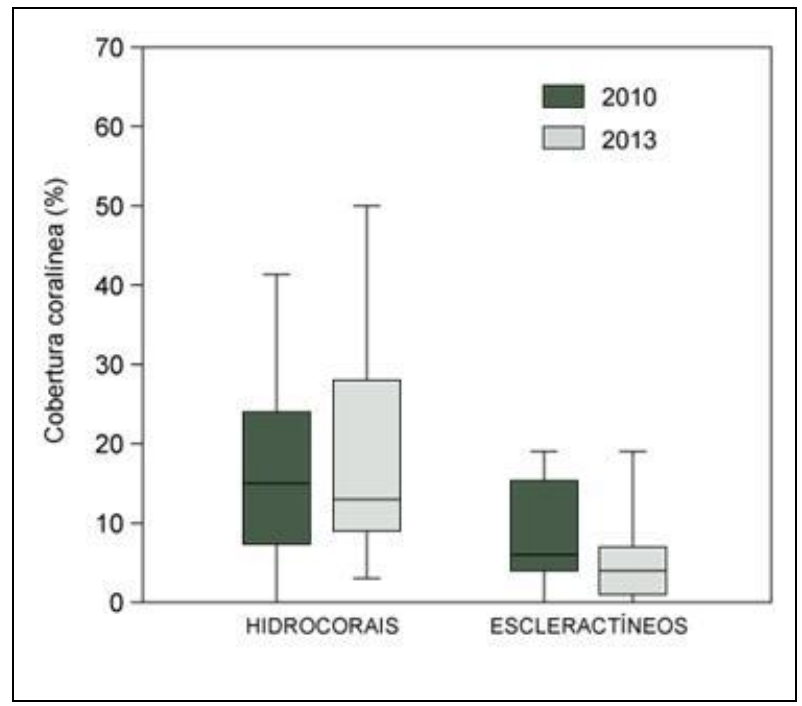

Figura 11 - Porcentagem relativa de grupos de corais (hidrocorais e escleractíneos) para os anos de 2010 e 2013 pelo método FOT.

A figura 12 ilustra a porcentagem de Millepora alcicornis em comparação com a porcentagem de cobertura das outras espécies de corais identificadas pelo FOT. Nota-se a contribuição desta espécie em particular na fauna recifal da área. 
Silveira, Camila BRASIL Louro da; FERREIRA, Beatrice Padovani; COXEY; Mariana S. Variação temporal nos recifes de corais de Maragogi, Apa Costa dos Corais (2010 - 2013).

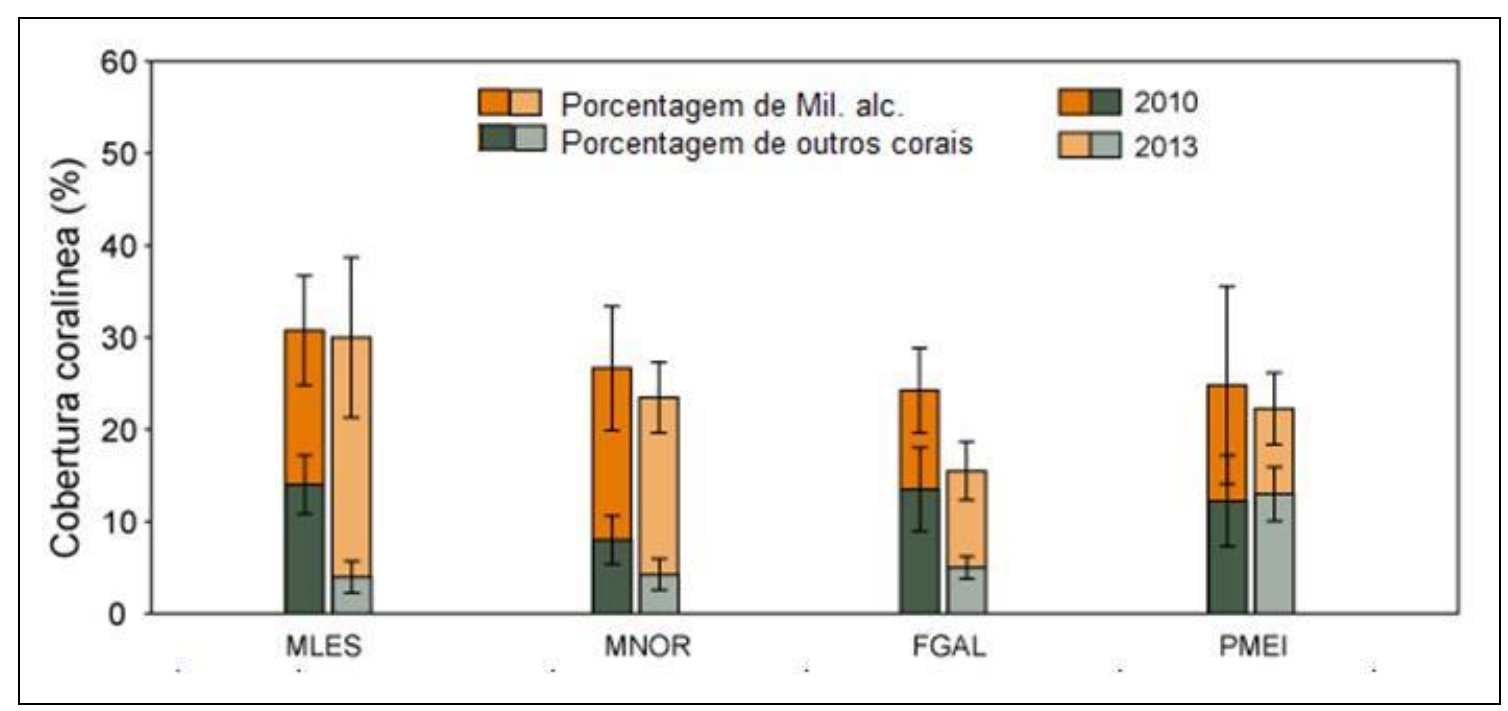

Figura 12 - Representação da porcentagem relativa de Millepora alcicornis comparada a porcentagem total de corais de outras espécies em cada sítio amostrado pelo FOT em 2010 e 2013.

Quando realizada a análise das categorias indicadoras, pelo método FOT, foram registradas mais do que as identificadas pelo PIT. Pelo FOT foram identificadas nos quadrats as seguintes categorias: NIA, ZOA, ESP, ECHI.

NIA: Alga Indicadora de Nutriente. Principalmente representada pelas cianobactérias.

ZOA: Zoantídeos. Principalmente representados pelos gêneros Zoanthus e Palythoa.

ESP: Esponjas.

ECH: Ouriços da espécie Echinometra lucunter.

A PERMANOVA-two way revelou que ao considerar as coberturas obtidas pelo método de Foto quadrats como um todo, os sites não são significativamente diferentes entre si, e as coberturas não variaram de forma significativa entre os anos. Uma vez que a cobertura coralínea é removida da análise, verifica-se apenas a similaridade entre os recifes em relação a cobertura dos outros organismos e substratos indicadores em 2010 e 2013. Nota-se também que os recifes se diferenciam entre si na composição da comunidade bentônica.

Tabela 8 - PERMANOVA two-way para comparação de coberturas de categorias indicadores obtidas pelo FOT para os fatores Ano e Site

\begin{tabular}{c|c|c|c|c}
\hline \multicolumn{3}{c|}{ COM COR } & \multicolumn{2}{c}{ SEM COR } \\
\hline Fator & $\mathrm{F}$ & $p$ & $\mathrm{~F}$ & $p$ \\
\hline Ano & 0,868 & 0,324 & 1,444 & 0,106 \\
\hline Site & 1,361 & 0,078 & 1,504 & $0,025^{*}$ \\
\hline Interação & $-1,314$ & 0,796 & - & 0,592 \\
& & & 1,121 & \\
\hline
\end{tabular}

Gráficos de Escalonamento Multidimensional (MDS) foram utilizados para facilitar a visualização dos resultados da estrutura da comunidade dos recifes estudados em 2010 e 2013 (Figura 13a) e da estrutura da comunidade coralínea dos recifes da área em 2010 e 2013 (Figura 13b). 


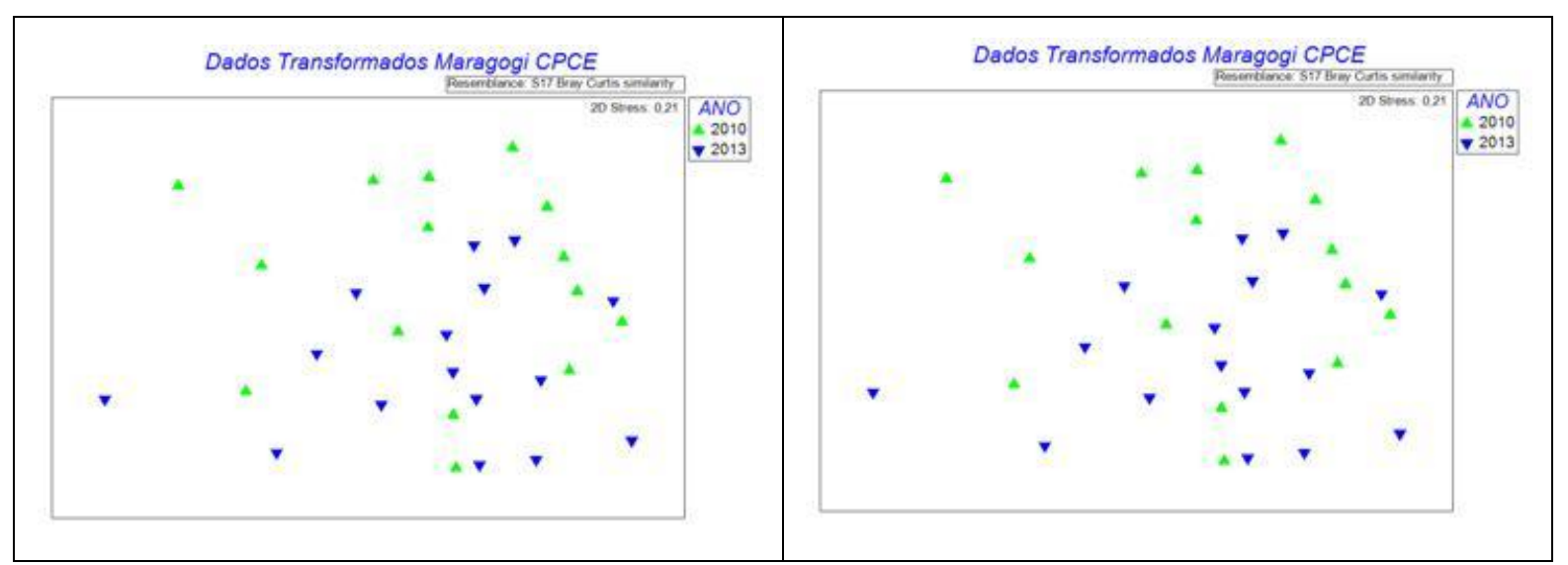

Figura 1 - MDS para composição da comunidade dos recifes de Maragogi obtida pelo método FOT: a) todos as classes indicadoras registradas; e b) comunidade coralínea em evidência.

\section{DISCUSSÃo}

O monitoramento constante, preferivelmente em escala anual ou menor, é uma das principais estratégias de manejo em áreas recifais. Esta estratégia provê a possibilidade de acompanhar possíveis variações de média escala no ambiente, e desta forma, alias o monitoramento ao manejo efetivo. Os recifes de corais de Maragogi, inseridos na Área de Proteção Costa dos Corais (APACC) vêm sendo monitorados pelo Protocolo Reef Check desde 2002 (Ferreira e Maida, 2006). Apesar desde esforço, dados quantitativos publicados acerca da cobertura coralínea na área ainda são esparsos. A APACC tem como objetivo harmonizar preservação ambiental com o uso público de forma sustentável, e desta forma, está sujeita a definição de diferentes zonas de uso. Os recifes apresentados neste trabalho estão atualmente classificados de duas formas: Zona de Visitação (Barreta do Moura Leste, Barreta do Moura Norte, Filha das Galés e Lastro do Jorge), e Zona de Preservação da Vida Marinha (Pedra do Meio). A inserção do recife de Pedra do Meio em ZPVM foi dada apenas em 2012/2013 (PMAPACC). Os dados aqui apresentados são também, portanto, muito importantes como base de cálculo para quaisquer mudanças que possam ocorrer a partir de 2013.

A realização dos censos em 2010 e 2013 nos mesmos locais e utilizando, na mesma área (Crista Recifal), dois métodos de pesquisa diferentes, permitiu inferir possíveis alterações ambientais ocorridas entre os anos e também, verificar os resultados em cada uma das metodologias.

Segundo os resultados deste trabalho, a maioria dos sítios estudados não revelou diferença significativa na média de cobertura coralínea total nas cristas recifais entre os anos de 2010 e 2013. O ano de 2010 é um ano especialmente interessante para o monitoramento, pois houve registros de branqueamento e mortalidade de corais associados a aumento de temperatura superficial marinha (SST) em diversas partes do mundo. Segundo Berkelmans e Willis (1999), anomalias de temperatura na ordem de $1^{\circ} \mathrm{C}$ são suficientes para causar branqueamento; e a continuidade desta anomalia pode ter como consequência branqueamento severo e mortalidade em massa. Os limites de resistência a temperaturas anômalas são, no entanto, dependentes de vários fatores, entre eles: espécie de coral afetado (Leão et al, 2003), a estrutura da comunidade recifal, distância da costa (Kikuchi et al, 2010). Em 2010, Ferreira et al (2013) observaram anomalias persistentes de mais de $1,5^{\circ} \mathrm{C}$ em recifes de corais oceânicos brasileiros (Atol das Rocas e Fernando de Noronha). Esta alta temperatura, associada ao evento El Niño 2009/2010, foi capaz de causar branqueamento em massa (em média 50\%) nas áreas estudadas. No mesmo ano, Miranda et al (2013) constataram oito semanas de anomalia máxima de $0,75^{\circ} \mathrm{C}$, suficientes para causar ao menos algum grau de branqueamento em mais de $50 \%$ das colônias estudadas. Posterior a este aquecimento, a porcentagem de colônias branqueadas foi reduzida a $5 \%$. As anomalias calculadas neste trabalho não foram altas e/ou persistentes o bastante para causar branqueamento em massa. A quantidade de colônias observada nos quadrats de foto com algum tecido branqueado foi desprezível em 2010, e pode 
Silveira, Camila BRASIL Louro da; FERREIRA, Beatrice Padovani; COXEY; Mariana S. Variação temporal nos recifes de corais de Maragogi, Apa Costa dos Corais (2010 - 2013).

ser também associada a eventos ambientais aleatórios e naturais (competição com algas, sombreamento ocasional, atividade de microorganismos, peixes, entre outros).

Os dois métodos empregados neste trabalho revelaram que a cobertura média total de corais se manteve estável entre 2010 e 2013 em Barreira do Moura Leste, Barreta do Moura Norte e Pedra do Meio (não são significativamente diferentes). Apesar do resultado estatístico, verificou-se que todos os sítios amostrados pelo PIT revelaram relativo aumento de cobertura neste período. Apenas um sítio (Filha das Galés), e somente quando acessado pelo PIT, revelou diferenças alterações temporais significativas de cobertura total. As médias totais nos quatro sites estudados corresponderam a $26 \%$ em 2010 e 31\% em 2013. Ferreira e Maida (2006) encontraram médias de cobertura de corais correspondentes às registradas neste trabalho nos primeiros censos realizados na área, em 2002 e 2003. Os autores supracitados registraram médias entre 22 e $33 \%$ para recifes em Maragogi, próximos dos pontos de pesquisa aqui apresentados.

A cobertura coralínea diferenciada associada ao ano de 2013 em relação a 2010, com um excepcional aumento em 2013, foi apenas presente em Filha das Galés. Uma análise mais específica revelou que a principal espécie responsável por esta diferenciação foi o mileporídeo Millepora alcicornis. O aumento de cobertura em questão foi de aproximadamente $11 \%$ em 2010 para quase $50 \%$ em 2013, que representaria um acréscimo de 300\% de cobertura em apenas três anos. A baixa cobertura total encontrada em 2010 pode ter siso resultado de impactos localizados sofridos na área (e.g depredação do espaço físico e colônias, por turismo, hidrodinamismo; etc). Sendo este o caso, os anos seguintes corresponderiam a um período de recuperação total.

Segundo estudos recentes, recifes de corais impactados no Caribe e Indo-Pacífico raramente chegam a taxas de recuperação maiores que $2 \%$ ao ano, e taxas "altas" (i. e, > $1,5 \%$.ano ${ }^{-1}$ ) são normalmente encontradas apenas em locais protegidos a mais de 15 anos (Selig e Bruno, 2010). Conjuntamente, em áreas prístimas na Grande Barreira de Corais na Austrália, que sofrem minimamente com impactos naturais, antrópicos e climáticos, o crescimento de corais pode atingir taxas de até 2,85\% ao ano (De'ath et al, 2012). Connell (1997), por sua vez, estima um período de ao menos 5-10 anos para uma recuperação expressiva na cobertura de corais pétreos. No entanto, é necessário salientar a importância da espécie Millepora alcicornis não só na área como um todo, mas em especial, em Filha das Galés. Segundo o PIT, em 2010 esta única espécie compôs 82\% de toda a fauna coralínea da crista no sítio; e, em 2013, este número aumentou para 89\%. Desta forma, as estimativas para recuperação de recifes de corais em áreas dominadas por corais pétreos (e.g Connell, 1997; Selig e Bruno, 2010; De'ath et al, 2012), não podem ser aplicadas a área, dado o rápido crescimento lateral e vertical (Wahle, 1980); e as diferentes estratégias de assentamento (Edmunds, 1999), reprodução (Lewis, 1996) e aumento de área de cobertura associada a Millepora alcicornis. Uma importante estratégia desta espécie de mileporídeo é a capacidade de crescimento dos galhos quebrados por algum impacto local (eg. fortes ondas, swell, quebramento por atividade antrópica) (Lewis, 2006). A fragmentação das colônias permite que apesar de um forte impacto (como furacões), fragmentos se fixem a substratos disponíveis criando novas áreas de crescimento e novas colônias. Edmunds (1999) ressalta a importância da disponibilidade de determinados substratos (i.e outras colônias vivas de $M$. alcicornis, rocha e areia) para o sucesso da fragmentação como estratégia de colonização e consequente dominância espacial. No caso de impacto localizado em Filha das Galés em 2010, esta pode ter sido uma das razões de aumento da cobertura de mileporas no ano de 2013.

Os resultados (PIT) também revelaram variações temporais na cobertura de categorias indicadoras, principalmente ACI (alga calcária incrustante ou alga coralinácea), TURF (turfs de alga) e ROC (rocha). Os resultados mais expressivos (i.e Turf e ACI) podem estar correlacionados a erros associados ao método utilizado e a superestima da cobertura de Millepora alcicornis, que serão discutidos de forma específica na comparação metodológica. As porcentagens de rocha, importante indicador por ser um viável substrato para o assentamento de recrutas de corais, foram muito baixas em 2010. As altas taxas de algas turf neste mesmo ano contribuem para a baixa disponibilidade de substrato duro, que por sua vez, podem causar uma diminuição no recrutamento de corais (Mc Clanahan et al, 2002). O aumento da pressão

Tropical Oceanography, Recife, v. 42, n. 2, p. 208-225, 2014. 
Silveira, Camila BRASIL Louro da; FERREIRA, Beatrice Padovani; COXEY; Mariana S. Variação temporal nos recifes de corais de Maragogi, Apa Costa dos Corais (2010 - 2013).

pesqueira diminui as taxas de herbivoria (McCook, 1999), que tende a aumentar as porcentagens de algas folhosas e turf no recife. No entanto, é importante notar a variação conjunta das coberturas de turf e de rocha, de forma inversa. Estes resultados podem indicar, inclusive, o aumento da ictiofauna herbívora associada ao recife (Hughes et al, 2007) entre 2010 e 2013: a pastagem ao mesmo tempo diminui as coberturas algáceas e disponibiliza o substrato rochoso, aumentando sua porcentagem relativa. Em contra partida, os resultados obtidos pelo método de Foto Quadrats não verificaram diferenças significativas na composição da crista dos recifes estudados entre 2010 e 2013.

Os resultados obtidos pelos dois métodos aplicados em conjunto nos recifes indicam algumas diferenças metodológicas importantes. Nadon e Stirling (2006) apontam as grandes variações espaciais em um mesmo recife como uma das dificuldades associadas a conectar estimativas visuais com dados quantitativos de alterações locais. Estas duas metodologias (PIT e FOT) são muitas vezes descritas como correspondentes (e.g Roelfsema et al, 2006), porém ao longo deste trabalho, verificou-se que adaptações específicas para a área se fazem necessárias. Ainda não há um consenso total sobre qual metodologia é a melhor ou mais preciso na determinação de coberturas específicas em recifes de corais (Nadon e Stirling, 2006). Verificamos que para o dado de cobertura total média, os métodos são correspondentes, porém, são necessários estudos futuros a fim de aumentar a confiabilidade dos dados na obtenção de coberturas específicas, principalmente as de menores porcentagens e de corais galhados de altura significante, como as Milleporas alcicornis da área.

\section{CONCLUSÃO}

Neste trabalho, concluiu-se a estabilidade, com tendências de aumento, da cobertura coralínea nos recifes de Maragogi. Os recifes desta área têm coberturas relativamente altas, normalmente maiores que $20 \%$. São locais de comunidade bentônica diversa, zoneados verticalmente e de suma importância ecológica, econômica e estrutural para a área. O manejo sustentável é necessário, assim como o monitoramento eficaz destes recifes. Propõe-se adaptações aos métodos atualmente utilizados, para que todas as zonas verticais dos sítios possam ser estudados de forma acurada, e que determinadas espécies coralíneas ou de categorias indicadoras não sejam subestimadas ou superestimadas. Desta forma, a detecção de alterações no ambiente poderá ser factível, e o ambiente poderá ser monitorado de forma ativa e sustentável.

\section{REFERÊNCIAS BIBLIOGRÁFICAS}

AMARAL, A. C. Z.; JABLONSKI, S. Conservação da biodiversidade marinha e costeira no Brasil. 2005

BEENAERTS, N.; BERGHE, E. V. Comparative study of three transect methods to assess coral cover, richness and diversity. Western Indian Ocean Journal of Marine Science, 4(1), 2938. 2007

BERKELMANS, R.; WILLIS, B. L. Seasonal and local spatial patterns in the upper thermal limits of corals on the inshore Central Great Barrier Reef. Coral Reefs, 18(3), 219-228. 1999

BROWN, B. E. Coral bleaching: causes and consequences. Coral reefs, 16(1), S129-S138. 1997

CASTRO, C. B.; PIRES, D. O. Brazilian coral reefs: what we already know and what is still missing. Bulletin of Marine Science, 69(2), 357-371. 2001

CONNELL, J. H. Disturbance and recovery of coral assemblages. Coral reefs, 16(1), S101S113. 1997

COSTA JR, O. S.; LEAO, Z. M. A. N.; NIMMO, M.; ATTRILL, M. J. Nutrification impacts on coral reefs from northern Bahia, Brazil. In Island, Ocean and Deep-Sea Biology (pp. 307-315). Springer Netherlands. 2000

DODGE, R. E.; LOGAN, A.; ANTONIUS, A. Quantitative reef assessment studies in Bermuda: a comparison of methods and preliminary results. Bulletin of Marine Science, 32(3), 745-760. 1982

Tropical Oceanography, Recife, v. 42, n. 2, p. 208-225, 2014. 
Silveira, Camila BRASIL Louro da; FERREIRA, Beatrice Padovani; COXEY; Mariana S. Variação temporal nos recifes de corais de Maragogi, Apa Costa dos Corais (2010 - 2013).

EDMUNDS, P. J. The role of colony morphology and substratum inclination in the success of Millepora alcicornis on shallow coral reefs. Coral Reefs, 18(2), 133-140. 1999

FERREIRA, B. P., MAIDA, M. Monitoramento dos recifes de coral do Brasil. MMA, Secretaria de Biodiversidade e Florestas. 2006

FERREIRA, B. P.; COSTA, M. B. S. F.; COXEY, M. S.; GASPAR, A. L. B.; VELEDA, D.; ARAUJO, M. The effects of sea surface temperature anomalies on oceanic coral reef systems in the southwestern tropical Atlantic. Coral reefs, 32(2), 441-454. 2013

GCMRN. Global Coral Reef MOnitoring Network. Disponível online em http://gcrmn.org GLYNN, P. W.; MATÉ, J. L.; BAKER, A. C.; CALDERÓN, M. O. Coral bleaching and mortality in Panama and Ecuador during the 1997-1998 El Niño-Southern Oscillation event: spatial/temporal patterns and comparisons with the 1982-1983 event. Bulletin of Marine Science, 69 (1), 79-109. 2001

GOREAU, T; McCLANAHAN, T.; HAYES, R.; STRONG, A. L. Conservation of coral reefs after the global bleaching event. Conservation Biology, 14(1), 5-15. 19982000

HOdGSON, G., W. KIENE, J. MIHALY, J. LIEBELER, C. SHUMAN, AND L. MAUN. Reef Check Instruction Manual: A Guide to Reef Check Coral Reef Monitoring Published by Reef Check, Institute of the Environment, University of California at Los Angeles. 2004

HOEGH-GULDBERG, O. Climate change, coral bleaching and the future of the world's coral reefs. Marine and Freshwater Research, 50(8), 839-866. 1999

HOEGH-GULDBERG, OVE, P. J. MUMBY, A. J. HOOTEN, R. S. STENECK, P. GREENFIELD, E. GOMEZ, C. D. HARVELL et al. "Coral reefs under rapid climate change and ocean acidification." Science 318, no. 5857: 1737-1742. 2007

HUGHES TP et al. Phase shifts, herbivory, and the resilience of coral reefs to climate change. Curr Biol 17:360-3652007

JACKSON, J. B., KIRBY, M. X., BERGER, W. H., BJORNDAL, K. A., BOTSFORD, L. W., BOURQUE, B. J., ... WARNER, R. R. Historical overfishing and the recent collapse of coastal ecosystems.

Science, 293(5530), 629-637. 2001

KIKUCHI RKP, LEAO ZMAN OLIVEIRA MDM. Conservation status and spatial patterns of AGRRA vitality indices in Southwestern Atlantic Reefs. Rev. Biol. Trop., vol.58, suppl.1, pp. 1-31. 2010ISSN 00347744.

KLEYPAS, J. A.; McMANUS, J. W.; AB MEÑEZ, LAMBERT. Environmental limits to coral reef development: where do we draw the line?. American Zoologist, 39(1), 146-159. 1999

LEÃO, Z. M. A. N.; TELLES, M. D.; SFORZA, R.; BULHÕES, H. A.; KIKUCHI, R. K. P. (). Impact of tourism development on the coral reefs of the Abrolhos area, Brazil. Biological

Conservation, 76(2), 215-216. 1996

LEÃO ZMAN, KIKUCHI RKP, TESTA V. (2003). Corals and coral reefs of Brazil. Em Cortês J (Ed.) Latin America Coral Reefs. Elsevier. Amsterdã, Holanda. pp. 9-52.

LEWIS, J. B. Biology and Ecology of the Hydrocoral< $\mathrm{i}>$ Millepora </i $>$ on Coral Reefs.

Advances in Marine Biology, 50, 1-55. 2006

MAIDA, M.; FERREIRA, B. P. Coral Reefs of Brazil: Overview and field guide. In: Proc. 8th Int. Coral Reef Sym., v. 1, p. 263-274, 1997

MCCLANAHAN, T. N.; POLUNIN,; T. DONE. (). Ecological states and the resilience of coral reefs. Conservation Ecology 6(2):18. 2002. [online]URL: http://www.consecol.org/vol6/iss2/art18

McCOOK, L. J. Macroalgae, nutrients and phase shifts on coral reefs: scientific issues and management consequences for the Great Barrier Reef. Coral reefs, 18(4), 357-367. 1999

MIRANDA R. J,; CRUZ I. C. S.; LEÃO ZMAN. Coral bleaching in the Caramuanas reef (Todos os Santos Bay, Brazil) during the 2010 El Nin o event. Latin American J Aquat Res. 2013 
Silveira, Camila BRASIL Louro da; FERREIRA, Beatrice Padovani; COXEY; Mariana S. Variação temporal nos recifes de corais de Maragogi, Apa Costa dos Corais (2010 - 2013).

NADON, M. O.; STIRLING, G. Field and simulation analyses of visual methods for sampling coral cover. Coral Reefs, 25(2), 177-185. 2006

NOAA. National Oceanic and Atmospheric Administration. Disponível online em http://www.noaa.gov

NYSTRÖM $M$ et al. Capturing the cornerstones of coral reef resilience: linking theory to practice. Coral Reefs 27:4, 795-8092008

RANAL, M. A.; SANTANA, D. G. D. How and why to measure the germination process?.

Brazilian Journal of Botany, 29(1), 1-11. 2006

ROBERTS, M.; MCCLEAN, C. J,; VERON, J. E.; HAWKINS, J. P,; ALLEN, G. R.; MCALLISTER.

Marine biodiversity hotspots and conservation priorities for tropical reefs. Science, 295, 12801284. 2002

ROELFSEMA, C. M.; PHINN, S. R.; JOYCE, K. E. (). Evaluating benthic survey techniques for validating maps of coral reefs derived from remotely sensed images. In; Proc 10th Int Coral Reef Symp (Vol. 1, pp. 1771-1780), 2006.

SELIG, E. R.; BRUNO, J. F. A global analysis of the effectiveness of marine protected areas in preventing coral loss. PLoS One, 5(2), e9278. 2010,

SHEPPARD, C. R.; SPALDING, M.; BRADSHAW, C.; WILSON, S. Erosion vs. recovery of coral reefs after 1998 El Niño: Chagos reefs, Indian Ocean. AMBIO: A Journal of the Human Environment, 31(1), 40-48. 2002

WAHLE, C. M. Detection, pursuit, and overgrowth of tropical gorgonians by milleporid hydrocorals: Perseus and Medusa revisited. Science, 209(4457), 689-691. 1980

WEST, J. M; SALM, R. V. Resistance and resilience to coral bleaching: implications for coral reef conservation and management. Cons. Biol. 17: 956-967. 2003

WILKINSON, C. Coral bleaching and mortality - the 1998 Event 4 years later and

bleaching to 2002. In: Status of Coral Reefs of the World: 2002, edited by C.Wilkinson, pp. 33-44, Global Coral Reef Monitoring Network and Australian Institute of Marine Science, Townsville, Australia, 2002.

WILKINSON, C. Status of coral reefs of the world: 2008. Townsville: Global Coral Reef Monitoring Network, 2008. 